\title{
BAGAIMANA KAPABILITAS DINAMIS DAN MANAJEMEN PENGETAHUAN BERPENGARUH KEPADA KINERJA PERUSAHAAN? : SEBUAH BANGUNAN MODEL KONSEPTUAL
}

\author{
Didin Kristinawati ${ }^{(1)}$ \\ J ann Hidajat Tjakraatmadja(2) \\ ${ }^{(1)(2)}$ School of Business and Management, ITB \\ email: didinwati@sbm-itb.ac.id
}

\begin{abstract}
ABSTRAK
Studi ini dimaksudkan untuk membangun hubungan konseptual antara manajemen pengetahuan dan kapabilitas dinamis yang akan berpengaruh terhadap kinerja organisasi. Pengetahuan yang diakuisisi, ditransfer, diinternaliasi, dan dikombinasikan melalui proses formal dan informal dalam model SECI akan menghasilkan pengetahuan baru bagi organisasi. Namun, repositori pengetahuan saja ternyata belum cukup untuk menaikkan kinerja, akan tetapi diperlukan kemampuan perusahaan untuk menciptakan, mengintegrasikan, memperbarui, dan memanfaatkan aset pengetahuannya, dimana kemampuan itu sendiri merupakan hasil belajar dan praktek. Oleh karenanya faktor-faktor yang membuat proses manajemen pengetahuan dapat berlangsung efektif perlu difasilitasi perusahaan, yakni yang berkenaan dengan budaya belajar, kesalingpercayaan, dan dukungan teknologi informasi. Dalam studi ini juga hendak merelasikan secara konseptual bahwa di era pengetahuan dan dinamika lingkungan yang cepat berubah, diperlukan karakter pekerja atau anggota organisasi yang memiliki kedalaman spesifikasi sekaligus keterbukaan pikiran dan kemampuan bekerjasama lintas divisi ataupun lintas disiplin yang disebut dengan T-shaped skill.
\end{abstract}

Kata kunci: kapabilitas dinamis, manajemen pengetahuan, habitat belajar, kinerja

\begin{abstract}
This study is aimed to develop a conceptual relationship between knowledge management and dynamic capabilities that will affect organizational performance. Knowledge is acquired, transferred, internalized, and combined through formal and informal processes in the SECI model will generate new knowledge for the organization. However, the knowledge repository per se is insufficient to boost performance. It needs a company's ability to create, integrate, modify and utilize its knowledge assets. The ability itself is the result of learning and practice within a company. Therefore, the factors that will create effective knowledge management process need to be facilitated by the company, which are related to learning culture, mistrust, and information technology support. In addition to the model, in the era of rapidly changing environmet, it is necessary to build members of organizations with $t$-shaped skill character namely expert in the knowledge specification as well as open-minded and capable to cooperate in cross-division.
\end{abstract}

Keywords: dynamic capability, knowledge management, learning habitat, performance, t-shaped skill

\section{PENDAHULUAN}

Bagaimana perusahaan mencapai kinerja yang berbeda-beda?, dapat dijelaskan dengan konsep keunggulan kompetitif (Penrose, 1959; Wernerfelt, 1984; dan Barney, 1991). Mengapa diatributkan kepada keunggulan kompetitif? Sebab perusahaan sudah sulit bersaing dalam keunggulan komparatif. Keunggulan kompetitif perusahaan hanya dapat ditempuh dengan penggunaan sumberdaya non fisik (intangible) yang paling berharga bagi perusahanan yaitu pengetahuan (Drucker, 1998).

Pengetahuan dipandang sebagai sumber strategis yang paling penting dengan argumen bahwa perbedaan sumber pengetahuan dan kemampuan untuk menciptakan dan memperbaharuinya merupakan faktor penentu keunggulan kompetitif perusahaan (Barney, 1991; Drucker, 1994; Bhatt dan Grover, 2005). Hasil penelitian Nelson dan Winter (1982) juga menyatakan pengetahuan dan kompetensi organisasi sebagai aset bisnis strategis.

Ketika masuk menjadi anggota organisasi atau menjadi karyawan perusahaan, setiap individu membawa pengetahuannya. Didalam perusahaan, pengetahuan yang dibawanya akan diasah, diperoleh pengetahuan dan pengalaman baru, atau pengalaman yang sudah dimiliki semakin dipertajam. Individu mengembangkan pengetahuan, ketrampilan, dan pengalamannya dalam organisasi melalui berbagai cara-cara yang dilakukan perusahaan secara formal sistematis, maupun secara informal untuk mengembangkan diri Tjakraatmadja dan Kristinawati (2017), sehingga dapat dikatakan telah terjadi proses belajar di dalam organisasi. 
Proses belajar bagi individu dipandang sebagai sarana pengembangan diri, agar dirinya semakin berpengetahuan, semakin berpengalaman, dan semakin bermanfaat bagi dirinya sendiri. Sementara bagi perusahaan, yang diharapkan adalah agar pengetahuan yang ada di kepala individu anggota organisasi tersimpan menjadi pengetahuan organisasi bahkan ketika individu tersebut pindah, berhenti, pensiun, atau pulang ke rumah. Proses pengelolaan pengetahuan individu menjadi pengetahuan organisasi ini terjelaskan oleh model proses manajemen pengetahuan yang dikemukakan oleh Ikujiro Nonaka (1995) yang dijelaskan dalam empat proses yaitu sosialisasi, ekstensifikasi, kombinasi, dan internalisasi (SECI).

Proses manajemen pengetahuan yang efektif tidak mungkin dapat berjalan tanpa terbangunnya habitat belajar yang kondusif (Tjakraatmadja dan Kristinawati, 2017). Habitat belajar yang dimaksud adalah budaya belajar dan kesalingpercayaan. Budaya belajar disini merefleksikan keinginan, semangat, dan kebutuhan untuk terus belajar bagi individu dalam organisasi. Adanya budaya belajar yang tinggi akan mendorong individu dalam organisasi untuk aktif mencari pengetahuan baru, atau meningkatkan kualitas maupun kuantitas pengetahuan yang dimiliki. Kegiatan transfer pengetahuan dapat terwujud apabila diantara anggota organisasi terdapat rasa saling percaya (Tjakraatmadja dan Kristinawati, 2017) sehingga tidak ada resistensi untuk membagikan pengetahuan yang dimiliki. Penjelasan sebelumnya menunjukkan bahwa meskipun pengetahuan ada di kepala setiap individu, tetapi pengetahuan juga terbentuk pada saat orang bekerja dan berkolaborasi setiap hari dalam tugas-tugasnya di tempat kerja, yang membentuk pengetahuan organisasi (Krzakiewicz, 2013). Nonaka dan Takeuchi (1995) menekankan pentingnya mengelola pengetahuan organisasi melalui proses penciptaan pengetahuan secara spiral yang terdiri dari: sosialisasi, eksternalisasi, kombinasi, dan internalisasi (SECI). Oleh sebab itu, diperlukan proses manajemen pengetahuan yang efektif yang dapat menciptakan dan melestarikan repositori pengetahuan organisasi.

Repositori pengetahuan saja ternyata belum cukup. Peneliti seperti Eisenhardt dan Santos (2002) berpendapat bahwa keunggulan kompetitif perusahaan tidak hanya terkait dengan repositori pengetahuan namun juga bersumber dari kemampuan perusahaan untuk menciptakan, mengintegrasikan, memperbarui, dan memanfaatkan aset pengetahuannya. Disinilah konsep kapabilitas dinamis (KD) menawarkan konsep bahwa perusahaan selalu berusaha untuk memperluas, memodifikasi, mengkonfigurasi ulang, atau bahkan benar-benar mengubah sumber daya dan pengetahuan nya untuk menciptakan nilai dalam dinamika lingkungan bisnis yang cepat berubah (Katkalo, Pitelis, \& Teece, 2010). Kapabilitas dinamis adalah kemampuan perusahaan untuk menyesuaikan sumber dayanya untuk menciptakan nilai dalam lingkungan yang berubah dengan cepat (Teece, Rumelt, Dosi, dan Winter, 1994).

Pembahasan pada tataran konsep dan penelitian empirik yang secara khusus membahas tentang hubungan manajemen pengetahuan dengan kapabilitas dinamis belum terlalu banyak, diantaranya Capeda dan Vera (2007) yang memotret bagaimana manajemen pengetahuan merupakan proses dibelakang kapabilitas dinamis. Tseng dan Lee (2014) melakukan penelitian empirik tentang hubungan antara manajemen pengetahuan yang efektif terhadap kapabilitas dinamis dan kinerja perusahaan di Taiwan, penelitian ini tidak memasukkan faktor habitat belajar. Zollo dan Winter (2002) menghubungkan pengembangan kapabilitas dinamis dengan pembelajaran kolektif. Mereka mengembangkan kerangka kerja untuk menciptakan kemampuan dinamis melalui tiga mekanisme pembelajaran yaitu: akumulasi pengalaman masa lalu, kodifikasi pengetahuan, dan proses artikulasi pengetahuan. Disinilah penulis tertarik untuk mengelaborasi model konseptual hubungan antara manajemen pengetahuan (untuk membangun dan memelihara repositori pengetahuan organisasi) dengan kapabilitas dinamis yang merupakan kemampuan organisasi untuk mendayagunakan repositori pengetahuannya, memodifikasi, mengkonfigurasi, atau bahkan mengubah pengetahuan organisasi untuk menciptakan nilai dan beradaptasi dengan lingkungan bisnis yang terus berubah.

Bagian selanjutnya menjelaskan tentang metodologi yang digunakan yaitu tinjauan pustaka sistematis (systematic literature review), hasil dari tinjauan pustaka sistematis dan model konseptual beserta instrumen pengukuran yang dipergunakan.

\section{METODE PENELITIAN}

Penelitian ini menggunakan metode tinjauan pustaka sistematis (Thorpe, Holt, Macpherson, dan Pittaway, 2005) untuk memenuhi tujuan penelitian. Terdapat tiga prosedur dasar dalam tinjauan sistematis mulai dari identifikasi referensi pustaka yang relevan, dilanjutkan dengan subyek dan jurnal terpilih, dan terakhir proses evaluasi dalam tahapan sebagaimana dijelaskan pada paragraf selanjutnya. 
Pada tahap pertama, identifikasi pustaka yang relevan, kami memilih artikel di beberapa basis data jurnal akademis, yaitu Scopus, EBSCO, Google Scholar and Proquest, dengan kata kunci terpilih yang terkait dengan kapabilitas dinamis (dynamic capability), manajemen pengetahuan (knowledge management), organisasi pembelajar (learning organization), kinerja (performance) dengan pencarian terpisah untuk masing-masing kata kunci ataupun dikombinasikan.

Selanjutnya, dipilih subyek dan jurnal terkait. Subyek preferensi penulis terkait dengan " dynamic capability", "knowledge management", "learning organization", "resource based view". Jurnal pilihan penulis adalah IIndustrial \& Corporate Change Journal, Strategic management Journal, Strategic Management Journal, Organization Science, Strategic Management Journal, Journal of Management Studies, Strategic Management Journal, International Journal of Management Reviews, International Journal of Management Reviews, Journal of Management.

Penulis juga melakukan tinjauan pustakan dari buku-buku yang sudah pernah terbit yang membahas topik terkait seperti buku "Strategi Implementasi Knowledge Management" (2017) untuk memperkaya pustaka. Setelah didapat hasil dari tinjauan pustakan sistematis untuk masing-masing subyek yang terkait manajemen pengetahuan, kapabilitas dinamis, kinerja, habitat belajar, teknologi informasi, dan $t$-shaped skill, selanjutnya dibangun relasi antar variabel yang didasarkan kepada hasil penelitian sebelumnya. Seperti misalnya relasi antara manajemen pengetahuan dan kapabilitas dinamis secara konseptual sudah disinggung oleh Eisenhardt dan Martin (2002), Zollo dan Winter (2004). Demikian pula untuk relasi yang dibangun oleh variabel yang berkaitan didasarkan kepada penelitian sebelumnya yang akan dijelaskan pada bagian hasil pembahasan dibawah ini.

\section{HASIL DAN PEMBAHASAN \\ Tentang Manajemen Pengetahuan}

Istilah manajemen pengetahuan (Knowledge Management) pertama kali diperkenalkan pada tahun 1986, dalam konferensi manajemen Eropa (American Productivity dan Quality Center, 1996). Belum ada satu definisi yang diakui secara umum sehingga pemahaman akan manajemen pengetahuan menjadi beragam, ambigu, dan besifat abstrak (Maier dan Hädrich, 2006). Akan tetapi, konsep tentang manajemen pengetahuan kemudian berkembang secara cepat dan menarik perhatian banyak pihak. Tabel 1 menyajikan beberapa definisi manajemen pengetahuan terpilih, yang sekiranya dapat memberikan gambaran untuk menemukan pola dan prinsip tentang manajemen pengetahuan.

Tabel 1menunjukkan beberapa pola umum tentang makna manajemen pegetahuan (Tjakraatmadja dan Kristinawati, 2017) yaitu: (1) Manajemen pengetahuan adalah sebuah disiplin individual, tim, dan akhirnya menjadi disiplin organisasi; (2) manajemen pengetahuan adalah alat manajemen untuk menghasilkan inovasi berbasis pengetahuan dengan benar dan cepat, melalui proses integrasi antara manusianya (knowledge workers), proses yang mencakup kebijakan, peraturan, sistem prosedur kerja, dan tata cara kerja serta teknologi yang secara sinergis mampu memperlancar proses manajemen pengetahuan; (3) manajemen pengetahuan adalah alat manajemen untuk memudahkan proses berbagi pengetahuan (sebagai intisari dari proses manajemen pengetahuan); (4) manajemen pengeatahuan adalah alat manajemen untuk memperkaya atau mereplikasi penggunaan pengetahuan/ pengalaman terbaik yang dimiliki organisasi, untuk memperluas penggunaannya dalam setiap unit bisnis terkait, dan tentu untuk mencapai sasaran organisasi dengan cara yang lebih efisien dan efektif; (5) manajemen pengetahuan intinya tentang bagaimana sebuah organisasi mengelola knowledge workers, mengidentifikasi pengetahuan yang mereka miliki, mendokumentasikan dan menyebarkan pengetahuan kepada unit kerja lain; (6) manajemen pengetahuan memfasilitasi proses kreatif, imajinatif dan/atau inventif melalui proses transformasi pengetahuan tasit menjadi pengetahuan eksplisit atau meremajakan pengetahuan untuk melakukan inovasi berbasis pengetahuan baru.

Kebutuhan dalam organisasi untuk selalu berdaptasi dengan lingkungan yang dinamis mengharuskan terjadinya penciptaan pengetahuan (knowledge creation) di dalam organisasi. Proses penciptaan pengetahuan seperti yang dijelaskan oleh Li dan Gao (2003) membutuhkan inovasi terusmenerus dalam organisasi untuk mencapai keunggulan kompetitif. Nonaka mempopulerkan konsep penciptaan pengetahuan di akhir 90-an (Nonaka dan Takeuchi, 1995). Penciptaan pengetahuan adalah proses perbaikan dari pengetahuan yang ada melalui proses penemuan pengetahuan baru, atau melalui proses refleksi atas pengalaman yang pernah dialami. Biasanya proses ini terjadi kalau karyawan memiliki sikap terbuka ketika Ia mendeteksi adanya kesalahan kerja dan 
Tabel 1. Definisi Manajemen Pengetahuan

\begin{tabular}{l|l}
\hline \multicolumn{1}{c|}{ Pencetus } & \multicolumn{1}{c}{ Pengertian } \\
\hline $\begin{array}{l}\text { Harkins, Carter, Timmins } \\
\text { (2000) }\end{array}$ & $\begin{array}{l}\text { KM merupakan suatu kerangka atau sistem yang didesain untuk } \\
\text { membantu perusahaan dalam menangkap, menganalisis, menerapkan, } \\
\text { dan menggunakan kembali pengetahuan agar keputusan yang dibuat } \\
\text { lebih cepat, pintar dan baik serta mencapai keuntungan yang kompetitif. }\end{array}$ \\
\hline Sveiby (1997) & $\begin{array}{l}\text { KM merupakan seni menciptakan nilai dari modal organisasi yang tidak } \\
\text { berwujud }\end{array}$ \\
\hline UNDP (2014) & $\begin{array}{l}\text { KM merupakan praktik menangkap, menyimpan, dan berbagi } \\
\text { pengetahuan sehingga kita bisa belajar dari masa lalu dan } \\
\text { menerapkannya di masa depan. }\end{array}$ \\
\hline Gurteen (1998) & $\begin{array}{l}\text { KM pada dasarnya membahas orang yang berbagi pengetahuan; belajar } \\
\text { dari satu sama lain dan bekerja sama secara lebih efektif. }\end{array}$ \\
\hline Bergeron (2003) & $\begin{array}{l}\text { KM adalah suatu strategi dalam mengoptimalkan bisnis dengan cara } \\
\text { mengidentifikasi, memilih, mengelola, menyaring, dan mengemas } \\
\text { informasi-informasi penting dalam suatu organisasi bisnis dengan tujuan } \\
\text { meningkatkan performa pegawai dan daya saing organisasi. }\end{array}$ \\
\hline Tjakraatmadja (2002) & $\begin{array}{l}\text { KM adalah langkah sistematik dalam mengelola pengetahuan organisasi, } \\
\text { untuk menciptakan nilai, dan keunggulan kompetitif. }\end{array}$ \\
\hline Davenport \& Prusak (1998) & $\begin{array}{l}\text { KM adalah penggabungan pengalaman, nilai, informasi yang bersifat } \\
\text { kontekstual, dan pandangan para ahli, yang menghasilkan pemikiran } \\
\text { tertentu. }\end{array}$ \\
\hline
\end{tabular}

berusaha untuk melakukan perbaikannya. Lalu bagaimana proses penciptaan pengetahuan di dalam sebuah organisasi itu berlangsung? Pada dasarnya, pengetahuan diciptakan dari pengetahuan yang telah ada. Lebih lanjut, Nonaka dan Takeuchi (1995) memaparkan adanya empat pola dasar kreasi pengetahuan, atau konversi antara pengetahuan individu dengan pengetahuan organisasi, yang mungkin terjadi di dalam sebuah organisasi, yang terkenal dengan konsep SECI, singkatan dari socialization (sosialisasi), externalization (eksternalisasi), combination (kombinasi) dan internalization (internalisasi).

Sosialisasi: Proses konversi dari pengetahuan taksit menjadi pengetahuan taksit lagi, atau menciptakan pengetahuan taksit melalui berbagi pengetahuan/ pengalaman secara langsung antara orang per orang (face-to-face). Sosialisasi merupakan proses pertukaran dan kreasi pengetahuan taksit yang didapatkan dari hasil interaksi dan berbagi pengalaman.

Proses sosialisasi bisa terjadi melalui proses transfer pengetahuan taksit dari senior menjadi pengetahuan taksit para juniornya. Pola ini terjadi ketika seorang staf senior membimbing (melatih, mentoring atau coaching) seorang staf yang baru bergabung. Staf junior tersebut akan menyerap atau meniru apa yang diajarkan seniornya. Si junior akan membangun pengetahuan taksit-nya sendiri berdasarkan hasil pengamatan atas pengetahuan taksit seniornya. Pola ini dapat terjadi baik untuk pembelajaran keahlian teknis ataupun pembelajaran akan hal-hal yang bersifat konseptual, seperti membangun budaya kerja atau kebiasaan-kebiasaan dalam perusahaan.

Eksternalisasi: Proses konversi dari pengetahuan taksit menjadi pengetahuan eksplisit, dimana knowledge-workers melakukan proses artikulasi pengetahuan taksit yang dimiliki mereka, atau mereka melakukan proses kristalisasi pengetahuan-pengetahuan taksit yang mereka miliki, dan mengubahnya kedalam bentuk eksplisit baru. Proses eksternalisasi merupakan proses transformasi pengetahuan taksit menjadi eksplisit, misalnya melalui kodifikasi, dan dibagikan dalam suatu kelompok (tacit to explicit)

Kombinasi: Proses konversi atau integrasi atau kombinasi dari beberapa pengetahuan eksplisit (dari praktik-praktik yang sudah ada di perusahaan) sehingga menjadi praktik terpadu dan terkait dalam perusahaan. Proses kombinasi merupakan proses yang sistematik dalam mengembangkan pengetahuan eksplisit. Pola ini bisa terjadi pada saat seorang staf membaca dokumen-dokumen (pengetahuan eksplisit) yang dimiliki perusahaan, seperti laporan dan studi kasus perusahaan, untuk kemudian dibuat dokumen baru yang lebih baik. Contohnya adalah pembuatan peta pengetahuan yang menggambarkan pengetahuan tasit yang telah dimiliki oleh para anggota dalam organisasi.

Internalisasi: Proses konversi dari pengetahuan eksplisit menjadi pengetahuan taksit, dimana terjadi 
proses berbagi pengetahuan eksplisit siap pakai tadi ke seluruh unit organisasi, dan berhasil dikonversi menjadi pengetahuan taksit oleh semua individu untuk dipakai secara rutin. Proses internalisasi merupakan proses belajar untuk mendapatkan pengetahuan taksit baru dalam praktek. Pembelajaran dan akuisisi pengetahuan yang dilakukan oleh anggota organisasi terhadap pengetahuan eksplisit, disebarkan ke seluruh anggota organisasi melalui pengalaman sendiri, sehingga manjadi pengetahuan taksit anggota organisasi. Contohnya adalah penggunaan peta pengetahuan oleh anggota organisasi untuk meningkatkan keterampilan yang ada dan pengetahuan yang akan mengarah pada peningkatan keunggulan kompetitif organisasi mereka.

Proses kreasi pengetahuan di atas dapat berlangsung secara langsung, tatap muka di kantor; atau secara virtual melalui email, teleconference; atau secara mental melalui proses berbagi pengetahuan, pengalaman, ide dan kepercayaan, atau sebagai relasi dimana orang bisa berbagi tujuan yang umum. Menurut Nonaka, membangun dan menyampaikan pengetahuan harus melibatkan emosi, perasaan, model mental, pengalaman, atau membutuhkan suasana kerja yang disebut "ruang empati”.

\section{Tentang Habitat Belajar}

Proses belajar organisasional merupakan proses interaksi di antara para anggota organisasi melalui proses belajar bersama atau berbagi pengetahuan/ pengalaman. Untuk mendorong terjadinya proses belajar organisasional yang intensif dan efektif, para anggota organisasi membutuhkan habitat belajar yang kondusif serta dukungan berupa fasilitas belajar yang tepat guna.

Faktor habitat belajar dalam organisasi pembelajar berfungsi sebagai media untuk terjadinya proses belajar bersama, untuk menghasilkan kecerdasan kolektif, yang dihasilkan dari hasil pemikiran bersama. Prof. Frans Mardi Hartanto (2009) adalah orang pertama yang mencetuskan pentingnya peran dan fungsi habitat belajar dalam organisasi masa kini. Habitat organisasi merupakan unsur yang sangat penting untuk memotivasi dan memberikan kesempatan agar para anggota organisasi mau dan mampu memunculkan prestasi terbaiknya. Habitat belajar dibangun oleh dua unsur penting yakni rasa saling percaya dan budaya untuk mau terus belajar.

Rasa saling percaya adalah suatu keyakinan yang digambarkan oleh perilaku dan kemampuan untuk membiarkan pikiran kita terbuka atas semua fakta, meyakini akan pentingnya komunikasi dan dialog secara etis. Suatu masyarakat yang kurang memiliki rasa saling percaya, akan bekerja dalam suatu sistem (legalitas ataupun aturan) formal, yang dalam hal ini negosiasi, kesepakatan, dan kekuasaan akan lebih dominan. Instrumen legalitas formal ini akan menyubtitusi rasa saling percaya sehingga pada akhirnya akan menimbulkan biaya ekonomi tinggi, yang oleh para ahli ekonomi sering disebut biaya transaksi (Hartanto, 2009).

Rasa saling percaya dalam sebuah organisasi dapat diindikasikan oleh: (1) Kuatnya rasa saling pengertian, yang tumbuh sebagai akibat adanya rasa percaya diri dan empati; (2) Kuatnya rasa akrab dan hangat dalam berkomunikasi, yang tumbuh sebagai akibat adanya rasa saling percaya dan rasa mampu untuk saling memposisikan diri; (3) Kuatnya kemampuan menyelesaikan konflik, yang tumbuh sebagai akibat adanya rasa mampu untuk saling menyesuaikan keyakinan dan cara berpikir; (4) Kuatnya semangat keterbukaan yang etis, yang tumbuh sebagai akibat adanya sikap terbuka untuk menerima saran atau kritik yang etis (Tjakraatmadja dan Kristinawati, 2017).

Budaya belajar yang dimaksudkan disini adalah sikap/perilaku toleran pada perbedaan pendapat dan kesalahan kerja, yang tumbuh sebagai akibat adanya keyakinan bahwa perbedaan dan kesalahan (yang tidak disengaja) merupakan hal yang humanis dan dapat digunakan sebagai pengalaman (sumber pengetahuan atau inovasi). Demikian pula budaya belajar dapat dilihat dari semangat belajar yang berkelanjutan (continues learning), yang tumbuh sebagai akibat adanya keyakinan bahwa pengetahuan tumbuh secara cepat sekali dan hanya dapat diikuti jika kita memiliki kebiasaan untuk terus belajar secara berkelanjutan (Tjakraatmadja dan Kristinawati, 2017).

\section{Tentang Dukungan Teknologi Informasi (TI)}

Dukungan teknologi informasi mencerminkan sejauh mana proses KM didukung oleh penggunaan TI. Beberapa penulis telah menemukan bahwa TI adalah aspek penting proses KM (Raven \& Prasser, 1996; Davenport \& Prusak, 1998; Lee \& Choi, 2003). TI memfasilitasi perolehan informasi dan penyimpanan. Dukungan teknologi informasi terefleksikan dengan indikator di perusahaan tersedia perangkat IT untuk : (i) kolaborasi; (ii) komunikasi dengan sesama pekerja; (iii) mencari dan mengakses informasi penting; (iv) simulasi dan prediksi (sesuai dengan konteks perusahaan). 


\section{Tentang Pekerja Tipe T (T-shaped Skill)}

T-shaped skill, atau pekerja tipe $\mathrm{T}$ adalah atribut untuk pekerja berpengetahuan dimana kiasan garis vertikal huruf ' $\mathrm{T}$ ' bermakna kedalaman pengetahuan atau keahlian di bidang tertentu. Sedangkan garis horizontal diatas huruf ' $T$ ' mengacu pada kemampuan untuk berkolaborasi dengan pekerja di disiplin ilmu lainnya, juga mencerminkan kemauan untuk menggunakan pengetahuan yang dihasilkan dari kolaborasi (Lee \& Choi, 2003).

Indikator yang dapat dipakai untuk pekerja tipe T diantaranya: (i) karyawan merupakan ahli dalam bidangnya.; (ii) dalam hal ketrampilan, karyawan tidak hanya memahami tugas sendiri tetapi juga tugas karyawan lain; (iii) karyawan dapat memberi saran terhadap tugas karyawan lain; (iv) karyawan dapat berkomunikasi baik pada divisi/ departemennya maupun divisi/ departemen lain.

\section{Tentang Kapabilitas Dinamis}

Pembahasan manajemen strategis, ada dua arus besar untuk memahami daya saing perusahaan. Pertama, pendekatan (Porter, 1979) yang berfokus pada analisis lingkungan eksternal perusahaan dimana struktur industri merupakan faktor penentu daya saing perusahaan. Kedua, pendekatan dan Wernerfelt (1984) dan Barney (1991) yang berfokus pada lingkungan internal perusahaan. Pendekatan kedua dikenal sebagai resource-based view (RBV). Dalam makalahnya yang berjudul "A resourcebased view of the firm", Wernerfelt mengemukakan istilah RBV yang menjadi dasar untuk pemahaman tentang teori perusahaan berbasis sumber daya. RBV menganggap bahwa faktor penting untuk unggul dari pesaing adalah sumber dayadan perusahaan yang terdiri dari sumber daya berwujud dan tidak berwujud yang dapat dikelola oleh perusahaan untuk bertahan hidup (Barney, 1991). Aset tidak berwujud adalah kompetensi, teknologi, pengetahuan, keterampilan, pengalaman, dan kapabilitas. Seperti yang dikemukakan Barney (1991), tidak semua sumber daya memiliki potensi untuk menjadi unik tidak mudah ditiru serta menguntungkan bagi perusahaan. Sehingga hanya pengetahuanlah yang disebutkan Barney berpotensi untuk menjadi sumberdaya yang unik tersebut.

Namun, RBV mendapatkan dikritik karena pengetahuan yang tersimpan dalam repositori perusahaan dianggap sebagai sesuatu yang pasif. Pengetahuan memang tersimpan, tetapi yang dibutuhkan perusahaan untuk menghadapi dinamika lingkungan lebih dari repositori itu. Kritik terhadap kekurangan RBV ini dapat dijawab oleh konsep kapabilitas dinamis yang dikembangkan pada akhir 1990an, yang berkonsentrasi pada kemampuan untuk mendayagunakan repositori pengetahuan dan menyelaraskannya dengan perubahan lingkungan bisnis yang dinamis.

Seringnya terjadi kebingungan dan pertukaran makna dalam ruang lingkup pembahasan kapabilitas dinamis, maka berikut ini diketengahkan definisi sumberdaya, kompetensi, kompetensi inti, dan kapabilitas. Definisi sumberdaya Wenerfelt terdiri dari aset berwujud dan tidak berwujud, sedangkan Ulrich dan Lake membedakan antara kompetensi yang berada pada tingkat individu dan kemampuan di tingkat organisasi. Prahalad dan Hammel (1990) mengusulkan kompetensi inti yang memiliki kesamaan dengan kapabilitas di tingkat organisasi. Demikian pula kompetensi inti Leonard-Barton (1995) memiliki kecenderungan didefinisikan sebagai kapabilitas di tingkat organisasi. Oleh karena itu, penulis merasa perlu untuk membedakan ruang lingkup dimana kompetensi berada pada ruang lingkup individual, dan kapabilitas untuk ruang lingkup organisasi. Definisi kapabilitas (tingkat organisasi) disintesis sebagai seperangkat kompetensi yaitu kemampuan, keterampilan, pengetahuan (Barton, 1992; Ulrich dan Lake, 1991) untuk membangun struktur dan proses internal dalam mengerahkan sumber dayanya (Amit dan Schoemaker, 1993) untuk memberikan keunggulan kompetitif.

Perusahaan selalu berusaha untuk memperluas, memodifikasi, mengkonfigurasi ulang, atau bahkan benar-benar mengubah apa yang sudah biasanya mereka kerjakan untuk menciptakan nilai dalam perubahan lingkungan yang dinamis (Katkalo dkk., 2010). Dalam hal ini, kapabilitas dinamis memainkan peran penting sebagai kemampuan perusahaan untuk menyesuaikan organisasi strukturalnya untuk menciptakan nilai dalam lingkungan yang berubah dengan cepat (Teece dkk, 1994). Sejak Teece mengeluarkan terminologi kapabilitas dinamis itulah, penelitian mengenai ini memperoleh perhatian yang luas dari mulai penelitian konsep hingga pembuktian empiris untuk saling memperkaya interpretasi terhadap definisi kapabilitas dinamis.

Konsep kapabilitas dinamis menurut Teece dkk. (1994) adalah bagian dari kompetensi yang memungkinkan perusahaan menciptakan produk atau proses baru dan merespons perubahan keadaan pasar. Kemudian direvisi menjadi kemampuan perusahaan untuk mengintegrasikan, membangun, dan mengkonfigurasi ulang kompetensi internal dan 
eksternalnya untuk mengatasi perubahan lingkungan yang cepat (Teece, Pisano, dan Shuen, 2000).

Eisenhardt dan Martin (2000) membahas kapabilitas dinamis dalam konteks menciptakan kemampuan tanpa menunggu krisis dari lingkungan eksternal, di mana kemampuan dinamis adalah rutinitas organisasi yang strategis sebagai proses untuk mengintegrasikan, mengkonfigurasi ulang, mendapatkan, dan melepaskan sumber daya. Zollo dan Winter (2002) mendefinisikan kapabilitas dinamis sebagai pola kerja kolektif yang dipelajari dan stabil, sehingga dengan itu organisasi secara sistematis menghasilkan dan memodifikasi rutinitas operasionalnya untuk peningkatan efektivitasnya.

Sementara itu, Zahra dan George (2002) mendefinisikan kapabilitas dinamis sebagai kemampuan yang berorientasi perubahan yang membantu perusahaan dalam meninjau ulang, mengkonfigurasi, dan menempatkan kembali dengan tepat sumber daya mereka untuk memenuhi perkembangan pasar dan strategi pesaing. Mereka mengasumsikan bahwa kapabilitas dinamis merupakan konsep yang penting dan berguna baik pada lingkungan bisnis dengan laju perubahan yang lambat maupun dalam lingkungan yang sangat cepat berubah.

Demikian pula, Helfat dan Peteraf (2003) mengemukakan bahwa kapabilitas dinamis melibatkan adaptasi dan perubahan selama organsiasi membangun, mengintegrasikan, atau mengkonfigurasi ulang sumber daya dan kemampuan lainnya. Argumen ini juga sejalan dengan Barreto (2010) yang menyatakan kemampuan dinamis sebagai potensi perusahaan untuk memecahkan masalah secara sistematis, dibentuk oleh kecenderungannya untuk mengidentifikasi peluang dan ancaman, membuat keputusan yang tepat dan berorientasi pasar, dan mengubah basis sumber dayanya.

Berdasarkan penjelasan tersebut, penulis memiliki kecenderungan dalam mendefinisikan kapabilitas dinamis sebagaimana Teece (2007) dan Barreto (2010) yang menyatakan kapabilitas dinamis merupakan kombinasi dari kapasitas, kompetensi dan kemampuan perusahaan untuk (i) mengidentifikasi/ merasakan peluang eksternal; (ii) mengakuisisi sumber daya eksternal, dan (iii) mengkonfigurasi ulang perubahan sumber daya internal; (iv) Memperbaharui sumber daya internal.

Studi oleh Ambrosini dan Bowman (2009) telah menggambarkan kapabilitas dinamis sebagai sebuah proses. Proses kapabilitas dinamis yang dirangkum dari peneliti-peneliti terkemuka adalah konstruksi, penempatan, rekonfigurasi, integrasi sumberdaya perusahaan, bahkan jika diperlukan akan mengeleminasi sumberdaya yang tidak memberikan keunggulan kompetitif (Teece, Pissano dan Shuen, 1997; Eisenhardt dan Martin, 2000; Zollo dan Winter, 2002; Zahra dan George, 2002).

Zollo dan Winter (2002) mengusulkan siklus evolusi pengetahuan yang mencakup akumulasi pengalaman, artikulasi pengetahuan dan kodifikasi pengetahuan sebagai proses kapabilitas dinamis. Sehingga kemampuan dinamis akan dihasilkan oleh aktivitas kolektif untuk belajar dan berbagi pengetahuan untuk mencapai tujuan perusahaan atau peningkatan kinerja. Berdasarkan hal tersebut, penulis berpendapat bahwa kemampuan dinamis harus didasarkan pada proses manajemen pengetahuan.

Konsep kapabilitas dinamis menurut Teece dan Pissano (1994) adalah bagian dari kompetensi yang memungkinkan perusahaan menciptakan produk atau proses baru dan merespons perubahan keadaan pasar. Kemudian direvisi menjadi kemampuan perusahaan untuk mengintegrasikan, membangun, dan mengkonfigurasi ulang kompetensi internal dan eksternalnya untuk mengatasi perubahan lingkungan yang cepat (Teece, Pissano dan Shuen, 1997).

Eisenhardt dan Martin (2000) membahas kapabilitas dinamis dalam konteks menciptakan kemampuan tanpa menunggu krisis dari lingkungan eksternal, di mana kemampuan dinamis adalah rutinitas organisasi yang strategis sebagai proses untuk mengintegrasikan, mengkonfigurasi ulang, mendapatkan, dan melepaskan sumber daya.

Zollo dan Winter (2002) mendefinisikan kapabilitas dinamis sebagai pola kerja kolektif yang dipelajari dan stabil, sehingga dengan itu organisasi secara sistematis menghasilkan dan memodifikasi rutinitas operasionalnya untuk peningkatan efektivitasnya.

Sementara itu, Zahra dan George (2002) mendefinisikan kapabilitas dinamis sebagai kemampuan yang berorientasi perubahan yang membantu perusahaan dalam meninjau ulang, mengkonfigurasi, dan menempatkan kembali dengan tepat sumber daya mereka untuk memenuhi perkembangan pasar dan strategi pesaing. Mereka mengasumsikan bahwa kapabilitas dinamis merupakan konsep yang penting dan berguna baik pada lingkungan bisnis dengan laju perubahan yang lambat maupun dalam lingkungan yang sangat cepat berubah.

Demikian pula, Helfat dan Peteraf (2003) mengemukakan bahwa kapabilitas dinamis melibatkan adaptasi dan perubahan selama organsiasi membangun, mengintegrasikan, atau mengkonfigurasi ulang sumber daya dan 
kemampuan lainnya. Argumen ini juga sejalan dengan Barreto (2010) yang menyatakan kemampuan dinamis sebagai potensi perusahaan untuk memecahkan masalah secara sistematis, dibentuk oleh kecenderungannya untuk mengidentifikasi peluang dan ancaman, membuat keputusan yang tepat dan berorientasi pasar, dan mengubah basis sumber dayanya.

Dari penjelasan diatas, penulis memiliki kecenderungan dalam mendefinisikan kapabilitas dinamis sebagaimana Teece (2007) dan Barreto (2010) yang menyatakan kapabilitas dinamis merupakan kombinasi dari kapasitas, kompetensi dan kemampuan perusahaan untuk (i) mengidentifikasi/ merasakan peluang eksternal; (ii) mengakuisisi sumber daya eksternal, dan (iii) mengkonfigurasi ulang perubahan sumber daya internal; (iv) Memperbaharui sumber daya internal.

Beberapa indikator kapabilitas dinamik diantaranya yang diturunkan dari definisi Teece dan Barreto diatas diantaranya: (1) Perusahaan secara sistematis mencari konsep/mode baru produksi / manufaktur melalui proses observasi di luar perusahaan; (2) Perusahaan secara sistematis melakukan forum diskusi untuk mengidentifikasi peluang baru; (3) Perusahaan aktif bekerja sama dengan mitra baru untuk mengembangkan kompetensi karyawan; (4) Hubungan karyawan adalah sumber informasi penting untuk mengembangkan modal virtual perusahaan; (5) Untuk setiap peluang bisnis baru, manajemen perusahaan telah melakukan proses transfer karyawan yang baik; (6) Perusahaan sudah memiliki sistem database yang memetakan tingkat kompetensi karyawan dengan cukup akurat.

\section{Tentang Kinerja}

Pembahasan kerangka teoretis mengenai hubungan antara kapabilitas dinamis dan kinerja telah dipublikasikan sebelumnya pada Jurnal Manajemen Indonesia (Kristinawati dan Tjakraatmadja, 2017). Pembahasan mengenai pengaruh antara kapabilitas dinamis dan kinerja menjadi penting untuk ditambahkan kedalam model, karena pada prakteknya perusahaan sebenarnya tidak terlalu menaruh perhatian secara sains mengenai hubungan antara manajemen pengetahuan, kapabilitas dinamis dan kinerja sebagaimana keingintahuan akademisi. Yang lebih penting bagi perusahaan adalah bagaimana kinerjanya dapat meningkat. Sehingga menjadi penting bagi peneliti untuk juga memperhatikan kebutuhan perusahaan atau industri dalam kegiatan penelitiannya.

Terkait manajemen organisasi, maka kinerja perusahaan merupakan bahasan yang menarik dan penting baik bagi akademisi maupun bagi praktisi bisnis. Dalam tradisi lama ilmu manajemen, kinerja perusahaan diukur dari kinerja finansial dimana kesuksesan perusahaan diasosiasikan dengan laba. Akan tetapi, seiring kebutuhan untuk dapat mengelola perubahan serta memberikan masukan untuk pengambilan keputusan manajemen, perspektif finansial saja tidak mencukupi, kinerja perusahaan perlu juga dilihat dari perspektif pelanggan, operasional ekselen, pembelajaran dan pertumbuhan (Venkatraman \& Ramanujam, 1986).

Perspektif finansial dapat diindikasikan dengan kemampuan perusahaan menghasilkan laba sesuai dengan target. Untuk indikator perspektif pelanggan diantaranya: (i) Pengguna produk merasa puas dengan kualitas produk yang dihasilkan perusahaan; (ii) Konsumen merasa puas dengan kualitas layanan purna jual. Perspektif operasional ekselen dapat diindikasikan diantaranya: (i) Efisiensi kerja perusahaan sudah cukup membanggakan; (ii) Perusahaan terus berinovasi untuk meningkatkan produktivitas kerja; (iii) Pengiriman produk pesanan konsumen perusahaan tidak pernah meleset dari kesepakatan jadwal. Perspektif pembelajaran dan pertumbuhan dapat diindikasikan diantaranya bahwa hasil pembelajaran di perusahaan mampu meningkatkan produktivitas kerja pekerja.

\section{Bangunan Model Konseptual}

Dari penggalian literatur sebagaimana yang dijelaskan diatas, maka dapat dibangun suatu model konseptual tentang bagaimana habitat belajar, manajemen pengetahuan, dan kapabilitas dinamis berpengaruh terhadap kinerja organisasi yang dipresentasikan pada Gambar 1.

Studi oleh Ambrosini dan Bowman (2009) telah menggambarkan kapabilitas dinamis sebagai sebuah proses. Proses kapabilitas dinamis yang dirangkum dari peneliti-peneliti terkemuka adalah konstruksi, penempatan, rekonfigurasi, integrasi sumberdaya perusahaan, bahkan jika diperlukan akan mengeliminasi sumberdaya yang tidak memberikan keunggulan kompetitif (Teece, Pissano dan Shuen, 1997; Eisenhardt dan Martin, 2000; Zollo dan Winter, 2002; Zahra dan George, 2002).

Zollo dan Winter (2002) mengusulkan siklus evolusi pengetahuan yang mencakup akumulasi pengalaman, artikulasi pengetahuan dan kodifikasi pengetahuan sebagai proses kapabilitas dinamis. 


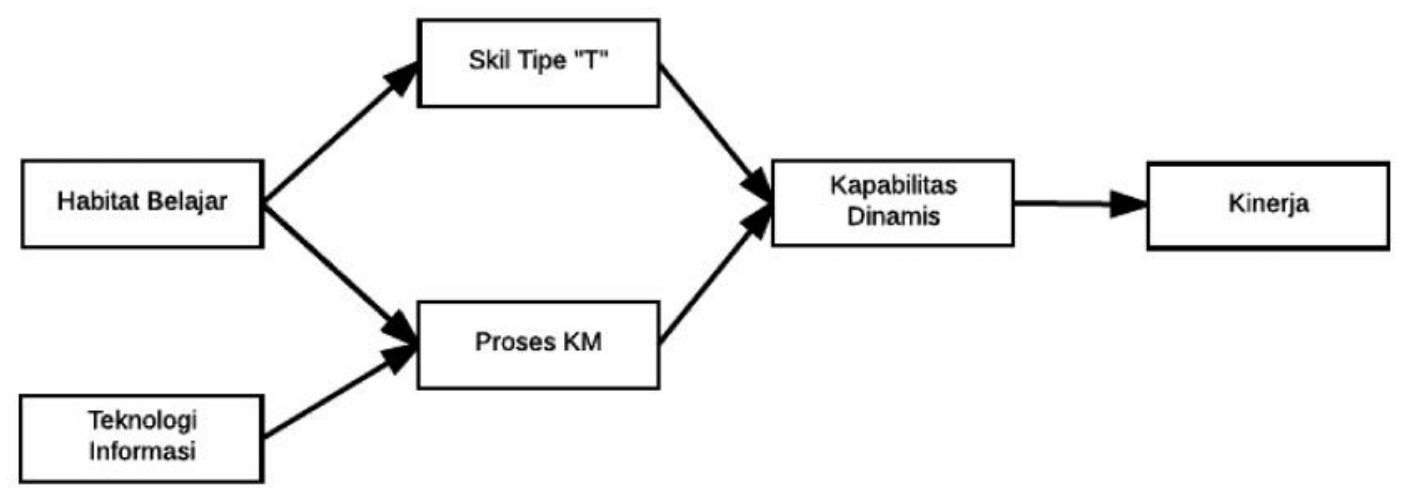

\section{Gambar 1. Model Konseptual Hubungan antara Manajemen Pengetahuan, Kapabilitas Dinamis dan Kinerja. \\ Sumber: Penulis}

Sehingga kemampuan dinamis akan dihasilkan oleh aktivitas kolektif untuk belajar dan berbagi pengetahuan untuk mencapai tujuan perusahaan atau peningkatan kinerja. Berdasarkan hal tersebut, penulis berpendapat bahwa kemampuan dinamis harus didasarkan pada proses manajemen pengetahuan yang efektif.

Untuk memiliki manajemen pengetahuan yang efektif, dimana anggota organisasi, secara aktif melakukan proses berbagi pengetahuan, diperlukan suatu habitat belajar yang kondusif yang terdiri dari kesalingpercayaan dan budaya untuk terus belajar (Tjakraatmadja and Kristinawati, 2017).

Dukungan teknologi informasi (TI) mencerminkan sejauh mana proses KM didukung oleh penggunaan TI. Beberapa penulis telah melakukan studi yang menunjukkan bahwa TI adalah aspek penting pendukung proses KM (Raven dan Prasser, 1996; Davenport dan Prusak, 1998; Lee dan Choi, 2003), dimana TI memfasilitasi perolehan informasi dan penyimpanan.

Konsep kapabilitas dinamis dalam studi ini membahas aspek rekonfigurasi internal perusahaan (misalnya penempatan proyek baru), kami berpendapat bahwa tipikal pekerja keterampilan berbentuk $\mathrm{T}$ akan secara positif berhubungan dengan Kemampuan Dinamis.

Kapabilitas dinamis merefleksikan kemampuan perusahaan untuk mencapai keunggulan daya saing, artinya kapabilitas dinamis mempunyai hubungan yang sangat erat dengan kinerja perusahaan. Penelitian terdahulu telah mencoba menunjukkan hubungan empiris antara kapabilitas dinamis dan kinerja. Seperti studi yang dilakukan oleh Griffith, Noble, dan Chen (2006) menunjukkan bahwa membangun kapabilitas dinamis dalam perusahaan akan meningkatkan kinerja perusahaan. D'Este (2002) memberikan bukti empiris dari 67 perusahaan farmasi di Spanyol, bahwa kapabilitas inovatif membuat perusahaan mampu melakukan perubahan, rekonfigurasi sumberdaya untuk secara efektif merespon permintaan pasar. Chien dan Tsai (2012) menunjukkan bukti empiris studi terhadap 132 manajer restoran pada jaringan restoran cepat saji di Taiwan bahwa kapabilitas dinamis meningkatkan kinerja restoran.

\section{KESIMPULAN}

Studi ini telah menghasilkan suatu bangunan model konseptual tentang bagaimana manajemen pengetahuan, dan kapabilitas dinamis berpengaruh terhadap kinerja organisasi. Bagi perusahaan, pengetahuan yang paling berharga adalah pengetahuan yang sudah menjadi milik organisasi. Untuk itu diperlukan manajemen pengetahuan yang efektif dengan menyediakan habitat belajar yang kondusif yakni terbangunnya rasa saling percaya sehingga merasa perlu untuk berbagi pengetahuan. Karena terdapat kesalingpercayaan dan termotivasi untuk berbagi pengetahuan, maka habitat belajar yang kondusif juga akan memperlancar terbentuknya profil karyawan yang memiliki keahlian tipe T, yakni ahli di bidangnya sekaligus mampu berkolaborasi. Teknologi informasi juga menjadi faktor yang mendukung efektifitas manajemen pengetahuan.

Namun, repositori pengetahuan organisasi sebagai produk dari manajemen pengetahuan yang efektif, belum cukup bagi perusahaan untuk memiliki kinerja yang bagus dalam iklim lingkungan usaha yang cepat berubah atau dinamis. Untuk itu diperlukan kapabilitas dinamis yang didahului oleh terkelolanya pengetahuan organisasi secara efektif.

Penelitian-penelitian sebelumnya membahas secara terpisah atau terpotong, misalnya meneliti hubungan antara habitat belajar dan manajemen pengetahuan saja, atau kapabilitas dinamis dan 
kinerja saja. Dengan demikian, diharapkan model konseptual ini telah mengisi gap dengan memberikan relasi yang komprehensif antara manajemen pengetahuan, kapabilitas dinamis, dan kinerja, dengan memasukkan faktor penting habitat belajar untuk mencapai manajemen pengetahuan yang efektif.

Membangun model konseptual ini, penulis bersinggungan dengan perusahaan padat pengetahuan di bidang teknologi transportasi. Sehingga yang dominan dalam alam pikiran penulis bahwa model konseptual ini relevan untuk konteks perusahaan manufaktur padat teknologi. Batasan ini perlu disampaikan sehingga studi lain dengan obyek yang berbeda dapat menyesuaikan. Sebab dimungkinkan dalam konteks yang berbeda, maka pemilihan indikatornya dapat berbeda pula.

Studi empirik menggunakan model ini perlu diperhatikan bahwa jumlah konstruk yang direlasikan cukup banyak yakni kinerja, kapabilitas dinamik, manajemen pengetahuan, T-shaped skill, habitat belajar, dan teknologi informasi. Sehingga dalam studi empirik perlu diperhatikan jumlah indikator yang dipergunakan. Karena semakin banyak indikator yang dipergunakan, akan memerlukan jumlah responden yang cukup untuk memenuhi kriteria. Jika penelitian merelasikan dua faktor saja seperti hubungan antara kapabilitas dinamik dan kinerja saja, contohnya pada studi awalan oleh Kristinawati dan Tjakraatmadja, (2017) maka indikator yang dieksplorasi dapat lebih banyak. Penulis menyarankan untuk studi kedepan dapat dieksplorasi indikatorindikator yang diperlukan oleh setiap variabel, kemudian melakukan analisis faktor untuk memilih indikator yang paling signifikan dan relevean, sesudahnya dapat diintegrasikan untuk analisis model strukturalnya.

\section{REFERENSI}

Ambrosini, V., \& Bowman, C. (2009). What are dynamic capabilities and are they a useful construct in strategic management? International Journal of Management Reviews. https://doi.org/10.1111/j.14682370.2008.00251.x

American Productivity \& Quality Center. (1996). Knowledge Management. Houston, Texas: Amer Productivity Center .

Amit, R., \& Schoemaker, P. J. H. (1993). Strategic assets and organizational rent. Strategic Management Journal. https://doi.org/10.1002/ smj.4250140105
Barney, J. (1991). Barney 1991.pdf. Journal of Management.

Barreto, I. (2010). Dynamic Capabilities: A review of past research and an agenda for the future. Journal of Management. https://doi.org/ 10.1177/0149206309350776

Bergeron, B. (2003). Essentials of Knowledge Management. New York: John Wiley and Sons Ltd.

Bhatt, G. D., \& Grover, V. (2005). Types of Information Technology Capabilities and Their Role in Competitive Advantage: An Empirical Study. Journal of Management Information Systems. https://doi.org/10.1080/07421222. 2005.11045844

Cepeda, G., \& Vera, D. (2007). Dynamic capabilities and operational capabilities: A knowledge management perspective. Journal of Business Research. https://doi.org/10.1016/j.jbusres. 2007.01.013

Chien, S., \& Tsai, C. (2012). Dynamic capability, knowledge, learning, and firm performance. Journal of Organizational Change Management. https://doi.org/10.1108/0953 4811211228148

D'Este, P. (2002). The distinctive patterns of capabilities accumulation and inter-firm heterogeneity: the case of the Spanish pharmaceutical industry. Industrial and Corporate Change. https://doi.org/10.1093/ icc/11.4.847

Davenport, T. H., \& Prusak, L. (1998). Working Knowledge: How Organizations Manage What They Know. Knowledge Creation Diffusion Utilization. https://doi.org/10.1109/EMR.2003. 1267012

Drucker, P. (1998). From capitalism to knowledge society. The Knowledge Economy. https:// doi.org///doi.org/10.1016/B978-0-7506-09210.50006-9

Drucker, P. F. (1994). The Post-Capitalist Society. Post-Capitalist Society. https://doi.org/ 10.1016/B978-0-7506-0921-0.50001-X

Eisenhardt, K. M., \& Martin, J. E. (2000). Dynamic Capabilities: What are they? Strategic Management Journal. https://doi.org/10.1002/ smj.233

Eisenhardt, K. M., \& Santos, F. M. (2002). Knowledge-Based View: A New Theory of Strategy? Handbook of Strategy and Management. https://doi.org/10.4135/9781848 608313 
Grant, R. M. (2010). Contemporary Strategy Analysis: Text \& Cases. International Journal of Management Education. https:// doi.org/10.1111/j.1467-9310.2006.00453_1.x

Griffith, D. A., Noble, S. M., \& Chen, Q. (2006). The performance implications of entrepreneurial proclivity: A dynamic capabilties approach. Journal of Retailing. https://doi.org/10.1016/ j.jretai.2005.11.007

Gurteen, D. (1998). Knowledge, Creativity and Innovation. Journal of Knowledge Management. https://doi.org/10.1108/13673279810800744

Harkins, P., Carter, L., \& Timmins, A. J. (2000). Linkage, Inc.'s best practices in knowledge management and organizational learning handbook/: case studies, instruments, models, research. Lexington, MA: Linkage Incorporated.

Hartanto, F. M. (2009). Paradigma Baru Manajemen Indonesia: Menciptakan Nilai dengan Bertumpu pada Kebajikan dan Potensi Insani. Bandung: Mizan.

Helfat, C. E., Helfat, C. E., Peteraf, M. a, \& Peteraf, M. a. (2003). The dynamic resource based view: Capability lifecycles. Strategic Management Journal.

Ikujiro Nonaka, H. T. (1995). The KnowledgeCreating Company - Ikujiro Nonaka, Hirotaka Takeuchi - Oxford University Press.

Katkalo, V. S., Pitelis, C. N., \& Teecey, D. J. (2010). Introduction: On the nature and scope of dynamic capabilities. Industrial and Corporate Change. https://doi.org/10.1093/ icc/dtq026

Kazimierz Krzakiewicz. (2013). Dynamic capabilities and knowledge management. Management, 17(2), 1-15. https://doi.org/ DOI10.2478/manment-2013-0051

Lee, H., \& Choi, B. (2003). Knowledge management enablers, processes, and organizational performance: An integrative view and empirical examination. Journal of Management Information Systems. https:// doi.org/10.2307/40398621

Leonard-Barton, D. (1995). Wellspring of knowledge. Boston: Harvard Business School, 1-17.

Maier, R., \& Hädrich, T. (2006). Centralized versus peer-to-peer knowledge management systems. Knowledge and Process Management. https:/ /doi.org/10.1002/kpm.244

Nelson, R., \& Winter, S. (1982). An Evolutionary Theory of Economic Change. Belknap Press: Cambridge, MA.
Nonaka, I., \& Takeuchi, H. (1995). KnowledgeCreating Company. Knowledge-Creating Company. https://doi.org/10.1016/S09694765(04)00066-9

Penrose, E. (1959). The Firm in Theory. In The Theory of the Growth of the Firm. https:// doi.org/10.1093/0198289774.001.0001

Porter, M. E. (1979). How Competitive Forces Shape Strategy. Harvard Business Review.

Prahalad, C. K., \& Hamel, G. (1990). The core competencies of the corporation. Harvard Business Review. https://doi.org/100-003-757

Raven, A., \& Prasser, S. G. (1996). Information Technology Support for the Creation and Transfer of Tacit Knowledge in Organizations. In Americas Conference on Information Systems (AMCIS) (p. 177). AMCIS. Retrieved from http://aisel.aisnet.org/amcis1996/177

Spencer, L. M., \& Spencer, S. M. (1993). Competence at Work/ : Models for Superior Performance. John Wiley \& Sons.

Sveiby, K. (1997). The Intangible Assets Monitor. Journal of Human Resource Costing \& Accounting. https://doi.org/10.1108/eb029036

Teece, D. (2007). Explicating dynamics capabilities: The nature and microfundations of (sustainable) enterprise performance. Strategic Management Journal. https://doi.org/10.1002/smj.640

Teece, D. J., Pisano, G., \& Shuen, A. (2000). Dynamic Capabilities and Strategic Management. In Nature \& Dynamics of Organizational Capabilities.

Teece, D. J., Rumelt, R., Dosi, G., \& Winter, S. (1994). Teece, D. J., Pisano, G., Shuen. A. 1997 Dynamic capabilities and strategic management, SMJ 18(7) 509-533.pdf. Journal of Economic Behavior \& Organization. https://doi.org/10.1016/0167-2681(94)90094-9

Thorpe, R., Holt, R., Macpherson, A., \& Pittaway, L. (2005). Using knowledge within small and medium-sized firms: A systematic review of the evidence. International Journal of Management Reviews. https://doi.org/10.1111/ j.1468-2370.2005.00116.x

Tjakraatmadja, J.H. (2002). Manajemen Transformasi Pengetahuan dalam Tim dan Organisasi Pembelajar. Institut Teknologi Bandung.

Tjakraatmadja, J., \& Kristinawati, D. (2017). Strategi Implementasi Knowledge Management (1st ed.). Bandung: Penerbit ITB.

Tseng, S., \& Lee, P. (2014). The effect of knowledge management capability and dynamic capability on organizational performance.... of Enterprise 
110 Matrik: Jurnal Manajemen, Strategi Bisnis dan Kewirausahaan Vol. 12, No. 2, Agustus 2018

Information Management. https://doi.org/ 10.1108/JEIM-05-2012-0025

Ulrich, D., \& Lake, D. (1991). Organizational capability: Creating competitive advantage. Academy of Management Executive, 5(1), 77-92. https://doi.org/10.5465/AME.1991. 4274728

Ulrich, D., \& Smallwood, N. (2004). Capitalizing on capabilities. Harvard Business Review. https://doi.org/Article

UN. (2014). Undp Knowledge Management Strategy Framework 2014 -2017. United Nations Development Programme.

Venkatraman, N., \& Ramanujam, V. (1986). Measurement of business performance in strategy research: A comparison of approaches. The Academy of Management Review.

Wang, C. L., \& Ahmed, P. K. (2004). The development and validation of the organisational innovativeness construct using confirmatory factor analysis. European Journal of
Innovation Management. https://doi.org/ 10.1108/14601060410565056

Wernerfelt. (1984). A Resource-based view of the firm. Wernerfelt, B. (1984). A ResourceBased View of the Firm. Strategic Management Journal. https://doi.org/10.1002/ smj.4250050207

Zahra, S. A., \& George, G. (2002). Absorptive capacity: A review, reconceptualization, and extension. Academy of Management Review. https://doi.org/10.5465/APBPP.2000.5438568

Zahra, S., Sapienza, H., \& Davidsson, P. (2006). Entrepreneurship and dynamic capabilities: A review, model and research agenda. Journal of Management Studies. https://doi.org/ 10.1111/j.1467-6486.2006.00616.x

Zollo, M., \& Winter, S. G. (2002). Deliberate learning and the evolution of dynamic capabilities. Organizational Science. https://doi.org/ 10.1287/orsc.13.3.339.2780 